\title{
O PROGRAMA MINHA CASA, MINHA VIDA E A PRODUÇÃO DO ESPAÇO URBANO NA CIDADE DE BOA VISTA - RR
}

\author{
THE PROGRAM MY HOUSE, MY LIFE AND THE PRODUCTION OF URBAN SPACE IN \\ BOA VISTA CITY - RR
}

\author{
Adriana Roseno Monteiro ${ }^{1}$ \\ Antonio Tolrino de Rezende Veras ${ }^{2}$
}

\section{Resumo}

Em 2009 - na segunda gestão do governo Luís Inácio Lula da Silva (2007 a 2010), uma nova conjuntura na política habitacional brasileira se descortina, com o lançamento do Programa Minha Casa, Minha Vida (PMCMV), destinado ao atendimento das famílias com renda de até 10 salários mínimos. Este programa tem como prerrogativa resolver o déficit habitacional dos segmentos sociais de menor renda. Assim, está pesquisa tem como objetivo principal enfocar o cenário em que se dá o PMCMV, a sua normatização e seu funcionamento, atentando para a implantação dos seus empreendimentos na cidade de Boa Vista/RR, bem como a produção do espaço urbano. Almejando alcançar o proposto, os procedimentos metodológicos adotados foram a revisão bibliográfica, documental e pesquisa de campo. Com isso foi possível compreender o contexto em que foi criado o PMCMV e a localização de seus empreendimentos na cidade de Boa Vista/RR, que vem se dando prioritariamente na zona Oeste e grande parte deles nos limites de sua malha urbana.

Palavras-chave: Programa Minha Casa, Minha Vida. Produção do espaço urbano. Cidade de Boa Vista/RR.

\begin{abstract}
In 2009 - in the government's second administration of Luís Inácio Lula da Silva (2007 to 2010), a new conjuncture in the Brazilian habitational politics occurs, with the release of My House, My Life Program, (MHMLP), destined to the attendance of the families with income of up to 10 minimum wages. This program has as prerogative to solve the habitational deficit of the social segments of smaller income. Like this, this research has as main objective to focus the scenery in what occurs the MHMLP, your regulation and your operation, looking at the implantation of your enterprises in the city of Good Vista/RR, as well as the production of the urban space. Longing for to reach it proposed, the adopted methodological procedures were the bibliographical revision, documental and field research. With that, it was possible to understand the context in that was created the MHMLP and the location of your enterprises in the city of Boa Vista/RR, that is giving if priority in the West zone and great part of them in the limits of your urban mesh.

Keywords: My House, My Life Program. Production of the urban space. City of Boa Vista/RR.

\footnotetext{
1 Mestrado em Geografia pelo Programa de Pós-Graduação em Geografia da Universidade Federal de Roraima. E-mail: drycaluz@yahoo.com.br

2 Professor em cursos de graduação e pós-graduação stricto sensu da Universidade Federal de Roraima (UFRR). Doutor em Geografia e pesquisador do Departamento de Geografia e do programa de PósGraduação em Geografia da Universidade Federal de Roraima. E-mail: tolrino@bol.com.br
} 


\section{INTRODUÇÃO}

A política habitacional brasileira ao longo das décadas foi permeada por avanços e retrocessos no atendimento da população de baixa renda, na qual a carência por moradias ainda não foi inteiramente solucionada. Em 2009, já na segunda gestão do governo Luís Inácio Lula da Silva, é lançado o programa habitacional Minha Casa, Minha Vida (PMCMV), destinado ao atendimento das famílias com renda de até 10 salários mínimos, com o escopo de enfrentar o déficit habitacional, estimular a geração de empregos e os investimentos no setor da construção civil.

Em 2008, a crise internacional se acentuou. Devido a isso, o governo brasileiro numa tentativa de se antecipar e evitar os possíveis efeitos da crise internacional, lança o PMCMV, que apesar de ter por finalidade sanar a carência habitacional das famílias de baixa renda, inicialmente, concentra os seus esforços em estimular a área da construção civil, que começou a sentir as consequências da crise econômica com a abertura de seus capitais na Bolsa de Valores, passando assim, a pressionar o governo por uma solução, que mediante a isso, lança o PMCMV.

Tomando como referência estas discussões, o objetivo principal da pesquisa é enfocar o cenário em que se dá o PMCMV, a sua normatização e seu funcionamento, atentando para a implantação dos seus empreendimentos na cidade de Boa Vista/RR, bem como a produção do espaço urbano. Haja vista isso, foi utilizado como procedimentos metodológicos: a pesquisa documental - na qual foi realizada através de leis, decretos, manuais, entre outros documentos sobre o PMCMV; a pesquisa bibliográfica - feita por meio de livros, artigos, dissertações, teses e; a pesquisa de campo - feita por meio de visitas e observação direta da localização dos empreendimentos do PMCMV na malha urbana da cidade de Boa Vista.

Com base no objetivo elencando juntamente com os procedimentos metodológicos este trabalho está estruturado em três seções, partindo de elementos teóricos e conceituais, para apresentar os resultados e as inferências da pesquisa.

Na primeira seção intitulada "O cenário em que se delineia o Programa Minha Casa, Minha Vida" faz uma apresentação da conjuntura em que se deu a criação do PMCMV e as suas expectativas iniciais.

Na segunda seção, chamada "Programa Minha Casa, Minha Vida: normatização e funcionamento" são expostos os marcos jurídicos, conceituais e normativos que regem o PMCMV, 
com vistas a compreensão de suas principais características, com ênfase na faixa de renda 1 (um) que é de até três salários mínimos ${ }^{3}$.

$\mathrm{Na}$ terceira seção, nomeada "Produção do espaço urbano: a localização dos empreendimentos do Programa Minha Casa, Minha Vida, faixa de renda 1 (um), na cidade de Boa Vista/RR" faz uma abordagem da inserção dos empreendimentos do PMCMV para a faixa de renda 1 (um) na malha urbana da cidade levando em consideração a produção do espaço.

\section{O CENÁRIO EM QUE SE DELINEIA O PROGRAMA MINHA CASA, MINHA VIDA}

Em 2008 os efeitos da crise internacional se acentuaram. O governo brasileiro se antevendo à sua repercussão negativa na conjuntura nacional, lança em 2009 o Programa Minha Casa, Minha Vida que apesar de seu viés social, inicialmente, atua como uma ação anticíclica, concentrando seus estímulos na área da construção civil. Aragão enfatiza que em 2009, parte do setor da construção civil, que já estava acessando o mercado de capitais para financiar a produção, passou a sentir os efeitos da crise econômica com a abertura de seus capitais na Bolsa de Valores, passando então, a pressionar o governo para que este tomasse alguma atitude que auxiliasse as empresas e como resposta foi lançado o PMCMV ${ }^{4}$.

O lançamento do PMCMV pelo governo de Luís Inácio Lula da Silva em março de 2009, cria condições de ampliação do mercado habitacional para o atendimento das famílias com renda de até 10 salários mínimos, estabelecendo um patamar de subsídio direto, proporcional à renda das famílias, buscando claramente impactar a economia através dos efeitos multiplicadores gerados pela indústria da construção civil. Bastos salienta que "Com o programa MCMV o processo de produção de novas unidades alavancou particularmente o setor da construção civil, que cresceu em números superiores à economia nacional, elevando também o número de empregos formais no setor". ${ }^{5}$

Por esse motivo o programa prioriza a construção de novas moradias em detrimento da compra das já existentes, visando aquecer o mercado imobiliário, como esclarece Corrêa o PMCMV se propõe a financiar e subsidiar imóveis novos, ou seja, a característica do programa requer a construção de moradias, e não a mera compra e venda de unidades habitacionais existentes,

\footnotetext{
${ }^{3}$ Faixa de renda 1 na segunda fase do PMCMV passou a contar com valores fixos, ou seja, de até $R \$ 1.600,00$.

${ }^{4}$ ARAGÃO, 2010.

${ }^{5}$ BASTOS, 2012, p. 27
} 
contribuindo para a redução do déficit habitacional, o fomento a geração de emprego e renda por meio do aumento do investimento na construção civil. ${ }^{6}$

Portanto, apesar de previsto no programa a requalificação de imóveis urbanos, tem se dado preferência à construção de novas UHS (unidades habitacionais existentes), ao invés de priorizar o aproveitamento de imóveis usados e desocupados que na maioria das vezes já estão dotados de infraestrutura básica. Para Corrêa estimular a ocupação desses imóveis poderia resultar em solução eficaz na redução do déficit habitacional, sendo uma alternativa à construção de novas habitações. Tais edificações vazias configuram ainda um peso para a sociedade, pois são em sua maioria, unidades habitacionais inadimplentes em relação aos impostos. Diante disso, readaptar os imóveis vazios, inicialmente construídos para a classe média, aproveitaria a infraestrutura urbana completa e a localização privilegiada das cidades, beneficiando as famílias de baixa renda. ${ }^{7}$

A implantação do PMCMV como forma de contornar possíveis efeitos da crise internacional, não reduz os avanços que o programa trouxe para a política habitacional brasileira, contudo, os objetivos econômicos não podem de maneira nenhuma sobrepor aos habitacionais e sociais.

Desse modo, intentando compreender melhor o PMCMV para a faixa de renda 1 (um), na seção a seguir faremos uma abordagem sobre a sua normatização e funcionamento.

\section{PROGRAMA MINHA CASA, MINHA VIDA: NORMATIZAÇÃO E FUNCIONAMENTO}

O PMCMV foi criado pela Medida Provisória no 459, publicada em 25 de março de 2009, e depois convertida na Lei Federal no 11.977, de 7 de julho 2009 que foi regulamentada pelo Decreto 6.962, de 17 de setembro de 2009. Da criação do PMCMV até 16 de junho de 2011, podemos considerar a primeira fase do programa, ou seja, PMCMV fase 1 (um).

A Lei no 11.977/09 foi modificada pela Medida Provisória 514, de 2010, que foi convertida na Lei 12.424, de 16 de junho de 2011 e regulamentada pelo Decreto no 7.499, também de 16 de junho de 2011, criando assim a segunda fase do programa, ou seja, o PMCMV fase 2 (dois).

O PMCMV 1 (um), fase inicial, 2009 a 2011, tinha como meta a construção de um milhão de moradias, em curto prazo, tendo para isso alocado $R \$ 34$ bilhões de reais ( $R \$ 25,5$ bilhões do Orçamento Geral da União, R\$ 7,5 bilhões do FGTS e R\$ 1 bilhão do BNDES - Banco Nacional de Desenvolvimento Econômico e Social).

\footnotetext{
${ }^{6}$ CORRÊA, 2012.

${ }^{7}$ CORRÊA, 2012.
} 
Este programa visa atender famílias de até 10 salários mínimos, assim distribuídas: 400 mil unidades habitacionais (UHS) para famílias que se enquadram na faixa de renda 1 (um) que é de zero a 3 salários mínimos; 400 mil UHS para famílias que se inserem na faixa de renda 2 (dois) que é acima de 3 a 6 salários mínimos e 200 mil UHS para as famílias da faixa de renda 3 (três) que é acima de 6 a 10 salários mínimos.

Para as famílias na faixa de renda de zero até 3 salários mínimos o subsídio é integral, com isenção do seguro e um comprometimento máximo de 10\% da renda do mutuário, com uma prestação mínima de $\mathrm{R} \$$ 50,00 mensais. Para a faixa de renda de 3 a 6 salários mínimos, há um aumento do subsídio parcial em financiamentos, com redução dos custos do seguro, acesso ao Fundo Garantidor da Habitação Popular (FGHab) e o comprometimento máximo de 20\% da renda do mutuário para o pagamento das parcelas da unidade habitacional (uh). Para a faixa de mais de 6 a 10 salários mínimos haverá estímulo à compra com redução dos custos do seguro e acesso ao FGHab.

Minha Casa, Minha Vida é um programa do governo federal realizado em parceria com os estados, municípios e Caixa Econômica Federal (CEF). Ele visa abranger capitais e respectivas regiões metropolitanas, municípios com mais de 100 mil habitantes, podendo contemplar em condições especiais municípios entre 50 e 100 mil habitantes, de acordo com o seu déficit habitacional. $^{8}$

Apesar de o PMCMV apresentar esse modelo participativo entre o governo federal, estados, municípios e CEF é nítido o papel de destaque que a iniciativa privada detém na concretização dos empreendimentos, tanto na faixa de renda 1 (um), como nas faixas 2 (dois) e 3 (três), que passam a ser atendidas exclusivamente pelo mercado imobiliário.

A CEF é o agente operacional e financeiro do PMCMV que é gerido pelo Ministério das Cidades, utilizando recursos do Fundo de Desenvolvimento Social (FDS), Fundo de Garantia por Tempo de Serviço (FGTS), Fundo de Arrendamento Residencial (FAR), do Banco Nacional de Desenvolvimento Econômico e Social (BNDES) e do Fundo Garantidor da Habitação Popular (FGHab). Ele foi incluído no Programa de Aceleração do Crescimento 2 (PAC 2), em 2010, situado como um de seus eixos.

Para famílias com renda de até 03 salários mínimos não há análise de risco de crédito e as condições para obtenção do imóvel são: não ter sido beneficiado anteriormente em programas de habitação social do governo; não possuir casa própria ou financiamento em qualquer unidade da

${ }^{8}$ CAIXA ECONÔMICA FEDERAL, 2010 - 2011. 
federação; estar enquadrado na faixa de renda familiar do programa; pagamento de $10 \%$ da renda durante 10 anos, com prestação mínima de $\mathrm{R} \$$ 50,00, corrigida pela TR (taxa referencial de juros) e registro do imóvel em nome da mulher; sem entrada e sem pagamento durante a obra; sem cobrança de seguro por morte e invalidez permanente-MIP e danos físicos do Imóvel - DFI. ${ }^{9}$

Além destes critérios nacionais para enquadramento no programa, podem ser criados pelos estados e municípios critérios adicionais, desde que aprovados pelos conselhos locais de habitação quando existentes e de acordo com a Política Nacional de Habitação e as regras estabelecidas pelo governo federal.

Em 2010 a meta de 1 milhão de habitações construídas tinha sido alcançada pelo PMCMV fase 1 (um). Portanto, em 16 de junho de 2011, já no governo de Dilma Rousseff (2011-2014) temos o lançamento oficial da segunda fase do PMCMV, ou seja, o PMCMV 2 (dois), no qual novas regras foram agregadas ao programa.

O PMCMV 2 (dois), 2011 a 2014, teve como meta a construção de 2 milhões de moradias com um investimento de $R \$ 71,7$ bilhões até 2014 , sendo $R \$ 62,2$ bilhões do Orçamento Geral da União e R\$9,5 bilhões do FGTS. Ele abrange as capitais estaduais e suas respectivas regiões metropolitanas, o Distrito Federal e os municípios com população igual ou superior a 50 mil habitantes. Pode ainda atender municípios com população entre 20 e 50 mil habitantes desde que contemple alguns requisitos: população urbana superior ou igual a 70\%; a taxa de crescimento da população superior a 5\%, entre o período de 2007 a 2010 e taxa de crescimento populacional superior à taxa verificada no respectivo estado, no período de 2000 a 2010.

Nesta segunda fase do PMCMV houve mudanças quanto as faixas de renda que agora passam a ser relacionada a valores fixos: faixa de renda 1 (um) - contempla as famílias com renda de até $R \$ 1.600,00$, que na fase 1 (um) do programa era de zero a três salários mínimos; faixa de renda 2 (dois) - famílias com renda acima $R \$ 1.600,00$ até $R \$ 3.100,00$, que na fase 1 (um) era acima de três a seis salários mínimos; e faixa de renda 3 (três) - famílias com renda acima de R\$ 3.100,00 até $R \$ 5.000,00$, que na fase 1 (um) do PMCMV era acima de seis a dez salários mínimos.

Houve mudanças também acerca da distribuição das UHS por faixa de renda. Do montante de 2 milhões de moradias: 60\% do total, ou seja, 1,2 milhões vão atender as famílias da faixa 1 (um) - até R\$ 1.600,00; 30\% do total, ou 600 mil UHS, vão contemplar as famílias da faixa 2 (dois) acima de R\$1.600,00 até R\$ 3.100,00 e 10\% ou 200 mil UHS vão beneficiar as famílias da faixa 3 (três) - acima de $R \$ 3.100,00$ até $R \$ 5.000,00$

\footnotetext{
${ }^{9}$ CAIXA ECONÔMICA FEDERAL, 2010 - 2011.
} 
O PMCMV 2 (dois) para as famílias com renda de até $R \$ 1.600,00$ com recursos do Fundo Arrendamento Residencial (FAR) funciona basicamente da mesma forma do PMCMV 1 (um): a União aloca os recursos por área do território nacional, levando em consideração os dados populacionais fornecidos pelo IBGE; os estados e municípios realizam gratuitamente o cadastramento das famílias, enquadrando-as nos critérios estabelecidos e após triagem as indicam a CEF; a CEF faz a análise das famílias utilizando os dados do Cadastro Único (CADÚNICO) e de outros cadastros; as construtoras apresentam os projetos às Superintendências Regionais da CEF, podendo fazer ou não em parceria com os estados e municípios; a CEF faz a análise simplificada dos projetos, contrata a operação, acompanha a execução da obra pela construtora (que se responsabiliza pela entrega dos imóveis prontos e legalizados), libera os recursos de acordo com o cronograma e concluído o empreendimento, a CEF faz a comercialização das UHS às famílias selecionadas.

Brasil esclarece que o processo de seleção para as famílias da faixa de renda 1(um) é realizado em quatro fases: ${ }^{10}$

1a fase: é feita a seleção de candidatos pelo município. Os candidatos deverão estar inscritos nos cadastros habitacionais dos municípios, estados ou Distrito Federal. $\mathrm{Na}$ seleção dos candidatos têm prioridade famílias desabrigadas, que perderam o seu único imóvel, ou ainda, residentes em áreas de risco ou insalubres; com mulheres responsáveis pela unidade familiar ou que possuem pessoas com deficiência. Reserva-se, portanto, no mínimo 3\% das UHS para atendimento aos idosos e às famílias que tenham pessoas com deficiência.

2a fase: é realizada a inserção no Cadastro Único (CADÚNICO), ou seja, a prefeitura deve providenciar a inclusão ou atualização dos candidatos selecionados no CADÚNICO para programas sociais do governo federal.

3a fase: é feita a apresentação dos indicados, ou seja, a relação de candidatos selecionados é oficializada na instituição financeira responsável.

4a fase: a instituição financeira faz a verificação das informações, ou seja, as informações dos candidatos selecionados são verificadas comparando com outros cadastros. O candidato que omitir ou prestar informação falsa é excluído do processo de seleção. A figura 01 sintetiza melhor todas estas informações:

10 BRASIL, [2013]. 
Figura 01 - Fluxograma exibindo o funcionamento do PMCMV para as famílias com renda de até R\$ $1.600,00$ com recursos do FAR

Estados e municípios fazem o cadastramento das
famílias e as indicam a CEF
Apresentam os projetos à
CEF
(Pode ser em parceria
com os estados e
municípios)

Fonte: Organização e elaboração pela autora, com base nos dados da Caixa Econômica Federal. ${ }^{11}$

Para obtenção do imóvel é feito um cadastro para análise, no qual constará: documentos pessoais; verificação do Cadastro Único (CADÚNICO); verificação do Cadastro Nacional de Mutuários (CADMUT); verificação do Cadastro Informativo de Créditos não quitados do Setor Público Federal (CADIN); e comprovação de renda (formal ou informal) somente para enquadramento no programa. ${ }^{12}$

Nas faixas de renda 2 (dois) e 3 (três) funciona da seguinte forma: a União e FGTS alocam os recursos; as construtoras/incorporadoras apresentam os projetos às Superintendência Regionais da CEF; a CEF analisa e após a comprovação da comercialização mínima exigida (30\% de unidades comercializadas ou $20 \%$ de unidades financiadas pela CEF) é assinado o Contrato de Financiamento à Produção; após as vistorias realizadas pela CEF, os recursos são liberados de acordo com o

${ }^{11}$ CAIXA ECONÔMICA FEDERAL, [2012? ].
${ }^{12}$ CAIXA ECONÔMICA FEDERAL, [2012? ]. 
cronograma; quando concluído o empreendimento a incorporadora/construtora faz a comercialização das unidades aos mutuários. ${ }^{13}$

Diferente do que ocorre na faixa de renda 1 (um) em que a comercialização das UHS é feita pela própria CEF, nas faixas de renda 2 (dois) e 3 (três) são realizadas pelas construtoras. Consequentemente, na faixa de renda 1 (um) o risco para as construtoras quanto à comercialização das UHS passa a não existir. Por conseguinte, o empreendedor, assume uma função de prestador de serviços de construção à CEF.

Nas faixas de renda 2 (dois) e 3 (três) o prazo para o pagamento pode ser de até 30 anos, com um comprometimento máximo de $20 \%$ da renda do beneficiário, com juros nominais de: $5 \%$ a.a. + TR para renda de até $\mathrm{R} \$ 2.325,00 ; 6 \%$ a.a. + TR para renda de até $\mathrm{R} \$ 2.325,01$ a $\mathrm{R} \$ 3.100,00$ e 8,16\% a.a. + TR para renda de até $\mathrm{R} \$ 3.100,01$ a 5.000,00.

\section{PRODUÇÃO DO ESPAÇO URBANO: A LOCALIZAÇÃO DOS EMPREENDIMENTOS DO PROGRAMA MINHA CASA, MINHA VIDA, FAIXA DE RENDA 1 (UM), NA CIDADE DE BOA VISTA - RR}

A atuação do PMCMV para a faixa de renda 1 (um) ${ }^{14}$ em Boa Vista/RR tem se consolidado através da construção dos seguintes empreendimentos: residencial Pérolas do Rio Branco I, construído em 2010; II, III, IV em 2013; V em 2014 e ainda os Pérolas do Rio Branco VI, VII, além do residencial Ajuricaba em fase de construção, em 2014, com previsão de entrega para 2015 - todos localizados no bairro Dr. Airton Rocha; Residencial Cruviana I e II entregues às famílias em 2011, localizados no bairro Equatorial; conjuntos Auaris, Makunaima e Uailã comercializados em 2013, localizados no bairro Cidade Satélite; o residencial Vila Jardim em fase de construção em 2014, com previsão de conclusão das obras em 2015, também situado no bairro Cidade Satélite e o Residencial Manaíra entregue aos beneficiários em 2014, localizado no bairro Laura Moreira. A figura 02 mostra a localização de cada um deles:

\footnotetext{
${ }^{13}$ CAIXA ECONÔMICA FEDERAL, [2012? ]

${ }^{14}$ No PMCMV, fase 1 (um), a faixa de renda 1 (um), era de zero a três salários mínimos. Já na segunda fase do programa, a faixa de renda 1 (um), passou a ser de até $\mathrm{R} \$ 1.600,00$.
} 
Figura 02 - Mapa de localização dos empreendimentos do PMCMV, faixa de renda 1 (um), em Boa

Vista/RR até 2014

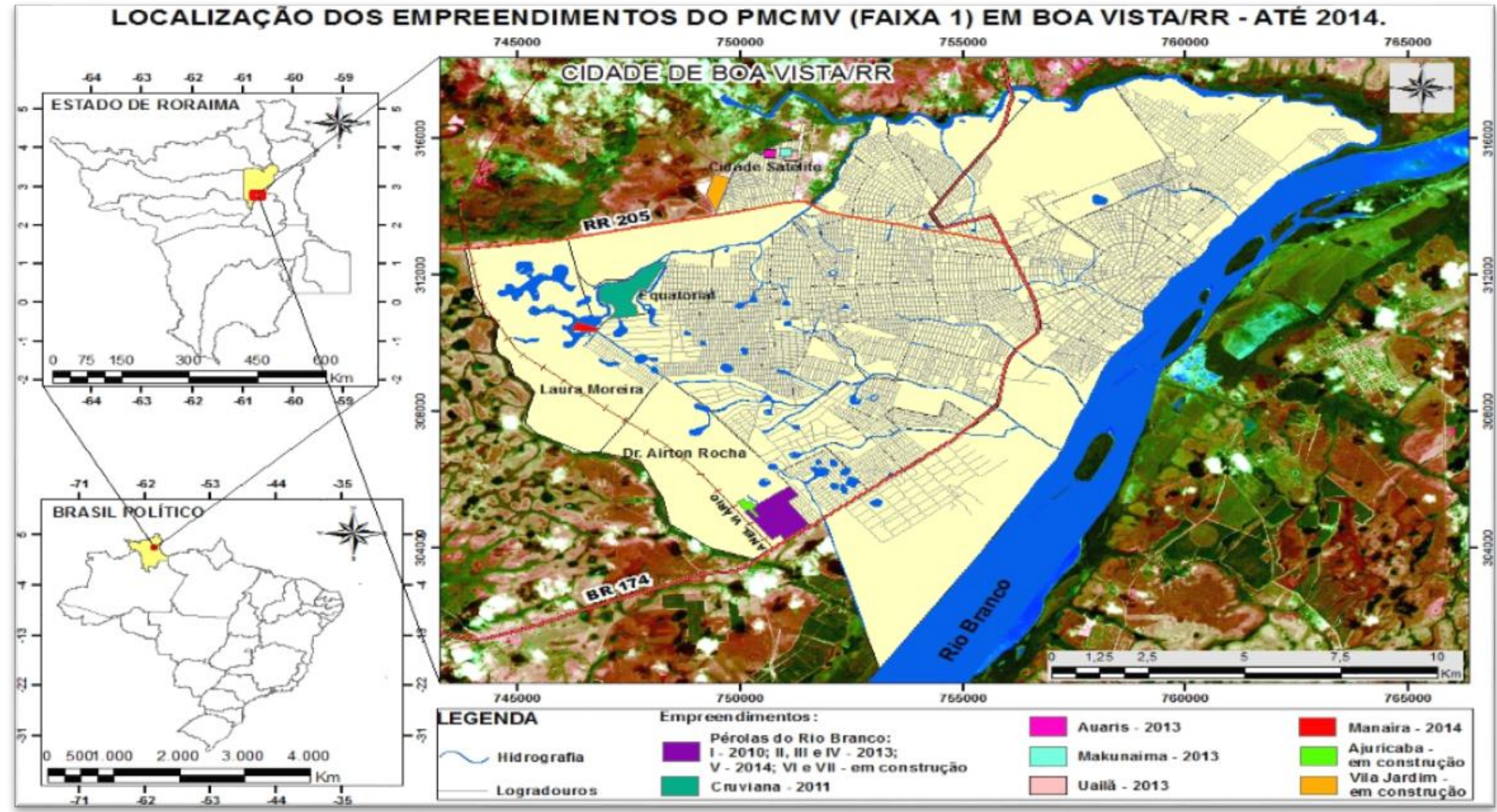

Organização e elaboração pela autora, utilizando a base cartográfica do IBGE e da Prefeitura Municipal de Boa Vista/RR e a imagem de satélite Landsat 8/OLI, órbita 232, ponto 58, de 2013.

Através da figura 02 podemos perceber que os empreendimentos do PMCMV para a faixa de renda 1 (um) estão contíguos à área já ocupada, todavia, grande parte deles estão localizados nos limites da malha urbana de Boa Vista.

Todos os empreendimentos para a faixa de renda 1 (um) estão inseridos na zona Oeste, porção da cidade caracterizada por bairros populares e onde estão localizados os terrenos mais baratos, constituindo-se na área que vem apresentado a maior tendência de crescimento de Boa Vista.

Para a implantação das UHS no âmbito do PMCMV deverão ser observadas algumas condições, previstas na Lei № 12.424, entre elas: 
Art. Para a implantação de empreendimento no âmbito do $\mathrm{PNHU}^{15}$, deverão ser observados:

Localização do terreno na malha urbana ou em área de expansão que atenda aos requisitos estabelecidos pelo Poder Executivo Federal, observado o respectivo plano diretor, quando existente;

Adequação ambiental do projeto; ${ }^{16}$

Levando em consideração estes critérios, os empreendimentos do PMCMV para a faixa de renda 1 (um) em Boa Vista estão inseridos na malha urbana ou nos limites da malha urbana e "na área urbana de expansão 1, voltada para a implantação de novos loteamentos"17, em observância, portanto ao respectivo Plano Diretor da cidade.

A adequação ambiental do projeto é outro critério essencial previsto na legislação do programa que deve ser considerado com rigor no planejamento urbano da cidade. A implantação de empreendimentos próximos a áreas ambientalmente frágeis requer esforços não somente na fase de implantação, mas um acompanhamento contínuo nesses locais para garantir a sua sustentabilidade. Em Boa Vista podemos destacar o caso do conjunto residencial Cruviana e Manaíra, que possuem expressivas áreas de preservação ambiental ao seu redor, sinalizando assim para uma necessidade maior de atuação dos órgãos públicos para se evitar uma degradação futura dessas áreas.

Nota-se que em Boa Vista os terrenos destinados à implantação do PMCMV para a faixa de renda 1 (um) vem se dando em grande parte nas franjas urbanas, e isto ocorre devido a vários fatores. Deve-se levar em conta que em áreas mais centrais a especulação imobiliária é mais intensa (principalmente num cenário de aumento do crédito para o financiamento do setor habitacional), assim, os preços dos terrenos são mais elevados, ultrapassando o valor estipulado para a construção de UHS para essa faixa de renda 1 (um), que em Boa Vista é de "62 mil" 18 para casas e apartamentos. Quando se aborda a questão da localização dos conjuntos habitacionais do PMCMV devemos considerar ainda a escala destes empreendimentos, principalmente os

15 O PMCMV de acordo com a Lei no 12.424, Art. 1o compreende os seguintes programas: "o Programa Nacional de Habitação Urbana - PNHU e o Programa Nacional de Habitação Rural - PNHR". Lembrando que o PNHR se destina a produção ou aquisição de novas UHS ou a requalificação de imóveis urbanos; já o PNHR tem a finalidade de subsidiar a produção ou reforma de imóveis aos agricultores familiares e trabalhadores rurais.

${ }^{16}$ BRASIL. Lei no 12.424, de 16 de junho de 2011, Art.5o- A, incisos I e II.

17 BOA VISTA. Lei Complementar no 924, de 28 de novembro de 2006, Art. 27, inciso I.

18 BRASIL, Portaria no 168 de 12 de abril de 2013. 
horizontais, que demandam grandes extensões de terras, que dificilmente poderiam ser encontradas em áreas centrais, na maioria das vezes já densamente ocupadas. Então a localização em áreas periféricas não se dá somente pelo barateamento dos terrenos, mas também pela maior disponibilidade destes.

Corrêa salienta que o preço e a disponibilidade dos terrenos se apresentam como elementos decisivos ao desenvolvimento do PMCMV, principalmente porque a indústria da construção civil procura por grandes glebas a fim de obter ganhos de escala que compensem o reduzido preço de venda dos imóveis voltados à faixa de renda 1 (um). Contudo, a especulação imobiliária, favorecida inclusive pelas ações do PMCMV, acaba por inflacionar o preço das terras mais bem localizadas, inviabilizando a construção dos empreendimentos sociais em áreas que, pela sua inserção na malha urbana, permitam um melhor acesso aos serviços e às oportunidades de trabalho, entre outras. ${ }^{19}$

Outro motivo para esta localização seria o fato de que grande parte destes terrenos foi disponibilizado pelo poder público, como por exemplo, no residencial Pérolas do Rio Branco I, II, III, IV e V e no residencial Cruviana I e II, os terrenos foram doados pela Prefeitura Municipal de Boa Vista, assim como nos conjuntos Auaris, Makunaima e Uailã tiveram os terrenos doados pelo Governo do Estado de Roraima, evidenciando mais uma vez, a atuação do ente público como indutor na direção do crescimento da cidade de Boa Vista para o setor Oeste, principalmente pelas camadas populares.

Para Soares o Governo Federal ao lançar o PMCMV, que tem como um de seus objetivos fomentar a economia através do incentivo à produção de UHS deixou a cargo do setor privado a iniciativa para a construção dos empreendimentos. Por meio do programa, foi disponibilizado crédito às construtoras, subsídio e crédito aos beneficiários, o que viabilizou a construção de moradias em larga escala. O papel que o Governo Federal poderia exercer na decisão sobre a localização dos conjuntos ficou restrito à exigência de que os conjuntos habitacionais fossem localizados em áreas contíguas à malha urbana. Da mesma maneira, a intervenção da CEF é restrita à análise da viabilidade dos empreendimentos e a verificação dos projetos quanto ao cumprimento dos créditos estabelecidos. ${ }^{20}$

O PMCMV exige para a construção de novas moradias, além da inserção na malha urbana ou em área de expansão, a utilização de terrenos que apresentem infraestrutura mínima. Desse

\footnotetext{
${ }^{19}$ CORRÊA, 2012

20 SOARES, 2012.
} 
modo, o PMCMV, apesar de nortear de forma geral a localização de seus empreendimentos e traçar especificações mínimas para a construção da uh para a faixa de renda 1 (um), o que se percebe, é que as construtoras possuem elevada capacidade decisória, influenciando sobremaneira onde e como serão instalados estes novos conjuntos habitacionais.

Cardoso et al. esclarecem que o governo federal conferiu à iniciativa privada os ditames da instauração do PMCMV, de forma a garantir um grande poder de decisão ao empresariado no que tange a definição e implantação dos empreendimentos financiados, ou seja, cabe às construtoras apontar onde o empreendimento será construído, a faixa de renda dos beneficiários e as características construtivas dos imóveis, restando às administrações municipais e à sociedade civil um papel coadjuvante neste processo..$^{21}$

O PMCMV ao mesmo tempo em que representa uma importante conquista para a política habitacional, tanto no que diz respeito ao número considerável de UHS, quanto ao fornecimento de largos subsídios, está atrelado à iniciativa privada, seguindo uma lógica mercantil de terras, própria do modo de produção capitalista, que favorece a implantação dos empreendimentos da população de menor renda predominantemente nas franjas do tecido urbano da cidade.

A implantação do PMCMV em Boa Vista deve contar com um planejamento não somente na construção do empreendimento, mas também em sua inserção na cidade, ou seja, a sua relação com as demais áreas a fim de evitar que o aumento populacional sobrecarregue os serviços públicos já existentes. Pois na medida em que se aumenta a quantidade de famílias morando em uma determinada área deve se aumentar também os equipamentos urbanos.

Para Balbino essa visão relacionada apenas com a expansão urbana pode acarretar sérios problemas, como a falta de infraestrutura dos equipamentos urbanos nas cidades para o suporte das novas edificações e a ineficiência de planejamento para a instalação de equipamentos comunitários como escolas, creches e hospitais, entre outras questões relacionadas à expansão urbana. 22

A se delimitar espaços na cidade para a construção de conjuntos habitacionais, geralmente em áreas mais distantes, se desenham vetores de expansão urbana, reforçando as diferenciações espaciais de acordo com as características socioeconômicas dos beneficiários. Aragão explica que ao fixar no território da cidade parcelas da população que possuem perfis socioeconômicos específicos, definidos pelas características dos programas habitacionais, as intervenções

\footnotetext{
${ }^{21}$ CARDOSO et al., 2013.

22 BALBINO, 2013.
} 
reforçaram ou estabeleceram as direções do crescimento da malha urbana e instituirão a diferenciação do espaço a partir das características dos habitantes beneficiados. ${ }^{23}$

A produção do espaço urbano com a construção de novos loteamentos ocorre de forma desigual e complexa com a incorporação de novas áreas. A construção de edificações, densificação do uso do solo, adensamento demográfico que forçam a extensão dos serviços coletivos e urbanos, tendem a estimular a valorização das áreas localizadas nos entremeios da cidade, realçando as diferenciações socioespaciais.

A produção de moradias de interesse social, em larga escala, ocasiona a expansão da malha urbana da cidade, através da utilização de extensas áreas e, consequentemente, a transformação da paisagem urbana. Bernardelli salienta que a moradia implementada através dos conjuntos habitacionais financiados com recursos públicos é uma das formas mais marcantes de produção e reprodução do espaço urbano, seja porque implica numa incorporação de áreas geralmente extensas, ou seja, pela transformação extremamente rápida da paisagem urbana. ${ }^{24}$

A figura 03 contextualiza melhor algumas características dos empreendimentos do PMCMV, faixa de renda 1 (um), na cidade de Boa Vista/RR, como: nome, contrato, fase do programa, faixa de renda e recursos, tipologia, número de UHS, data em que os empreendimentos se tornaram aptos à entrega, nome das construtoras e o valor em milhões.

\footnotetext{
${ }^{23}$ ARAGÃO, 2010.

${ }^{24}$ BERNARDELLI, 2004.
} 
Figura 03 - Quadro mostrando algumas especificações dos empreendimentos do PMCMV, faixa de renda 1 (um), em Boa Vista - RR.

\begin{tabular}{|c|c|c|c|c|c|c|c|c|c|}
\hline & Empreendimento & Contrato & $\begin{array}{l}\text { Fase do } \\
\text { PMCMV }\end{array}$ & $\begin{array}{c}\text { Faixa de } \\
\text { renda/recursos }\end{array}$ & Tipologia & $\begin{array}{l}\text { № de } \\
\text { UHS }\end{array}$ & $\begin{array}{l}\text { Apto a } \\
\text { entrega }\end{array}$ & Construtora & $\begin{array}{c}\text { Valor } \\
\text { (Milhões) }\end{array}$ \\
\hline 1 & $\begin{array}{c}\text { Residencial } \\
\text { Pérolas do Rio } \\
\text { Branco I }\end{array}$ & $0307.140-87$ & 1 & Faixa 1 - FAR & $\begin{array}{l}1 \text { - Casa } \\
\text { térrea }\end{array}$ & 50 & 20/11/2010 & $\begin{array}{l}\text { Renovo } \\
\text { Engenhar }\end{array}$ & $1.950 .000,00$ \\
\hline 2 & $\begin{array}{l}\text { Residencial } \\
\text { Cruviana I }\end{array}$ & 0295.537-09 & 1 & Faixa 1 - FAR & $\begin{array}{l}1 \text { - Casa } \\
\text { térrea }\end{array}$ & 500 & $19 / 05 / 2011$ & $\begin{array}{l}\text { Paralella } \\
\text { Engenhar }\end{array}$ & $19.500 .000,00$ \\
\hline 3 & $\begin{array}{l}\text { Residencial } \\
\text { Cruviana II }\end{array}$ & $0295.542-74$ & 1 & Faixa 1 - FAR & $\begin{array}{l}1 \text { - Casa } \\
\text { térrea }\end{array}$ & 500 & $19 / 05 / 2011$ & $\begin{array}{c}\text { Centro Norte } \\
\text { CO }\end{array}$ & $19.500 .000,00$ \\
\hline 4 & $\begin{array}{c}\text { Residencial } \\
\text { Pérolas do Rio } \\
\text { Branco II }\end{array}$ & 0367.701-30 & 2 & Faixa 1 - FAR & $\begin{array}{l}1 \text { - Casa } \\
\text { térrea }\end{array}$ & 67 & $14 / 10 / 2013$ & $\begin{array}{l}\text { Centro Norte } \\
\text { CO }\end{array}$ & $3.505 .625,34$ \\
\hline 5 & $\begin{array}{c}\text { Residencial } \\
\text { Pérolas do Rio } \\
\text { Branco III }\end{array}$ & 0368.593-42 & 2 & Faixa 1 - FAR & $\begin{array}{l}1 \text { - Casa } \\
\text { térrea }\end{array}$ & 222 & $30 / 10 / 2013$ & $\begin{array}{l}\text { Renovo } \\
\text { Engenhar }\end{array}$ & $11.684 .033,66$ \\
\hline 6 & $\begin{array}{c}\text { Residencial } \\
\text { Pérolas do Rio } \\
\text { Branco IV }\end{array}$ & $0376.705-67$ & 2 & Faixa 1 - FAR & $\begin{array}{l}1 \text { - Casa } \\
\text { térrea }\end{array}$ & 228 & $30 / 10 / 2013$ & $\begin{array}{l}\text { Paralella } \\
\text { Engen }\end{array}$ & $11.698 .427,93$ \\
\hline 7 & Conj. hab. Auaris & 0299.557-31 & 1 & Faixa 1 - FAR & 2- Apt. & 208 & $20 / 12 / 2013$ & Engexata & $8.944 .000,00$ \\
\hline 8 & $\begin{array}{l}\text { Conj. hab. } \\
\text { Makunaima }\end{array}$ & 0299.558-45 & 1 & Faixa 1 - FAR & 2- Apt. & 208 & $20 / 12 / 2013$ & Engexata & $8.944 .000,00$ \\
\hline 9 & Conj. hab. Uailã & 0299.559-50 & 1 & Faixa 1 - FAR & 2- Apt. & 208 & $20 / 12 / 2013$ & Engexata & $8.944 .000,00$ \\
\hline 0 & $\begin{array}{l}\text { Resid. Pérolas do } \\
\text { Rio Branco V }\end{array}$ & 0376.706-71 & 2 & Faixa 1 - FAR & $\begin{array}{l}1 \text { - Casa } \\
\text { térrea }\end{array}$ & 450 & $20 / 01 / 2014$ & $\begin{array}{c}\text { Centro Norte } \\
\text { CO }\end{array}$ & $27.272 .712,40$ \\
\hline 1 & $\begin{array}{l}\text { Residencial } \\
\text { Manaíra }\end{array}$ & 0397.073-69 & 2 & Faixa 1 - FAR & $\begin{array}{l}1 \text { - Casa } \\
\text { térrea }\end{array}$ & 250 & $21 / 03 / 2014$ & $\begin{array}{c}\text { Centro Norte } \\
\text { CO }\end{array}$ & $15.500 .000,00$ \\
\hline 2 & $\begin{array}{c}\text { Residencial } \\
\text { Pérolas do Rio } \\
\text { Branco VI }\end{array}$ & 0421.042-01 & 2 & Faixa 1 - FAR & $\begin{array}{l}1 \text { - Casa } \\
\text { térrea }\end{array}$ & 412 & $\begin{array}{l}\text { Em fase de } \\
\text { construção }\end{array}$ & $\begin{array}{c}\text { Recel } \\
\text { Terraplenag } \\
\text { em e } \\
\text { construções } \\
\text { Ltda. }\end{array}$ & $25.544 .000,00$ \\
\hline 3 & $\begin{array}{c}\text { Residencial } \\
\text { Pérolas do Rio } \\
\text { Branco VII }\end{array}$ & 0424.148-35 & 2 & Faixa 1 - FAR & $\begin{array}{l}1 \text { - Casa } \\
\text { térrea }\end{array}$ & 135 & $\begin{array}{l}\text { Em fase de } \\
\text { construção }\end{array}$ & $\begin{array}{c}\text { Centro Norte } \\
\text { CO }\end{array}$ & $8.370 .000,00$ \\
\hline 4 & $\begin{array}{l}\text { Residencial Vila } \\
\text { Jardim }\end{array}$ & 0396.201-97 & 2 & Faixa 1 - FAR & 2- Apt. & 2992 & $\begin{array}{l}\text { Em fase de } \\
\text { construção }\end{array}$ & $\begin{array}{c}\text { CMT } \\
\text { Engenharia }\end{array}$ & $185.501 .459,25$ \\
\hline 5 & $\begin{array}{l}\text { Residencial } \\
\text { Ajuricaba }\end{array}$ & - & 2 & Faixa 1 - FDS & $\begin{array}{l}1 \text { - Casa } \\
\text { térrea }\end{array}$ & 200 & $\begin{array}{l}\text { Em fase de } \\
\text { construção }\end{array}$ & $\begin{array}{l}\text { Recel } \\
\text { Terraplenag } \\
\text { em e } \\
\text { construções } \\
\text { Ltda. }\end{array}$ & $12.400 .000,00$ \\
\hline
\end{tabular}

Fonte: Organização e elaboração pela autora, com base em dados obtidos com a Gerência de Habitação da CEF em Boa Vista/RR, atualizados até outubro de 2014. 
Com exceção do residencial Ajuricaba que está incluído na modalidade do PMCMV Entidades e utiliza recursos provenientes do Orçamento Geral da União (OGU), depositados ao Fundo de Desenvolvimento Social (FDS) que é "destinado ao financiamento de projetos de investimento de relevante interesse social nas áreas de habitação popular, saneamento básico, infraestrutura urbana e equipamentos urbanos", ${ }^{25}$ todos os demais empreendimentos construídos pelo PMCMV fase 1 (um) e 2 (dois) utilizaram recursos do Fundo de Arrendamento Residencial (FAR), que foi criado pela Lei no 10.188, de 12 de fevereiro de 2002.

Os recursos do FDS destinam-se ao financiamento de empreendimentos contratados por meio de entidades organizadoras e os recursos oriundos do FAR são designados para o financiamento dos projetos habitacionais desenvolvidos por construtoras e incorporadoras.

O PMCMV Entidades funciona de modo diferenciado do PMCMV com recursos do FAR. No PMCMV com recursos do FAR, os estados e municípios realizam o cadastramento das famílias, de acordo com os critérios estabelecidos e após triagem as indicam à CEF e são as construtoras que apresentam os projetos às Superintendências Regionais da CEF, podendo fazer ou não em parceria com os estados e municípios.

No PMCMV Entidades, quem é o principal responsável por todo este processo é a Entidade Organizadora (EO), representada por cooperativas habitacionais ou mistas, associações e entidades privadas sem fins lucrativos. Só poderá atuar no programa a Entidade Organizadora que estiver previamente habilitada pelo Ministério das Cidades. No caso do residencial Ajuricaba a Entidade Organizadora é a Associação das Donas de Casa do bairro Caranã.

Por meio do PMCMV fase 1 (um) e faixa de renda 1 (um) tivemos em Boa Vista a implantação de 50 UHS no residencial Pérolas do Rio Branco I, 1000 UHS no residencial Cruviana, 208 UHS no conjunto Auaris, 208 UHS no conjunto Makunaima e 208 UHS no conjunto Uailã, totalizando 1.674 moradias.

Já o PMCMV fase 2 (dois) e faixa de renda 1 (um) foram construídas no residencial Pérolas do Rio Branco II: 67 UHS; no III, 222 UHS; no IV, 228 UHS; no V, 450 UHS; no residencial Manaíra 250 UHS; e estão em fase de construção: 412 UHS no Pérolas do Rio Branco VI; 135 UHS no Pérolas do Rio Branco VII; no residencial Ajuricaba 200 UHS; e no residencial Vila Jardim mais 2992 UHS, representando um total de 4.956 UHS construídas e em construção nesta segunda etapa programa.

${ }^{25}$ BRASIL. Decreto no 103, de 22 de abril de 1991, Art. 1ㅇ. 
Logo, a quantidade de UHS inseridas na cidade por meio do PMCMV para o atendimento das famílias com renda de até $\mathrm{R} \$ 1.600,00$ reais foi de 6.630 , resultante do somatório das UHS da fase 1 (um) e 2 (dois) do programa, construídas e em construção até 2014.

A implementação de um programa de grande dimensão como o PMCMV traz transformações significativas na configuração do espaço urbano. A utilização muitas vezes de extensas áreas para a implantação dos empreendimentos horizontais acarreta a expansão da malha urbana e aumenta a demanda por equipamentos e serviços urbanos. Por isso é necessárias avaliações contínuas a fim de reparar possíveis falhas e garantir o crescimento organizado da cidade de Boa Vista.

\section{CONSIDERAÇÕES FINAIS}

Em 2008, o governo brasileiro visando contornar os efeitos da crise internacional na conjuntura nacional, lança o PMCMV que apesar de apresentar um viés social, inicialmente atua como uma ação anticíclica, concentrando seus estímulos na área da construção civil - setor que já sentia os reflexos negativos da crise e passou a pressionar o governo por uma solução.

Com a instituição do PMCMV, em março de 2009 na gestão do governo de Luís Inácio Lula da Silva, houve uma dinamização da política habitacional criando condições de ampliação do mercado imobiliário para o atendimento das famílias com renda de até 10 salários mínimos, estabelecendo um patamar de subsídio direto, proporcional à renda das famílias, bem como um impulso na área da construção civil e elevação na geração de empregos no setor.

No entanto, convém ressaltar que a implantação do PMCMV como forma de se antever aos efeitos da crise internacional, não reduz os avanços que o programa trouxe para a política habitacional brasileira, contudo, os objetivos econômicos não podem de maneira nenhuma sobrepor aos sociais.

A atuação do PMCMV para a faixa de renda 1 (um) em Boa Vista/RR tem se consolidado através da construção de diversos empreendimentos, localizados prioritariamente nas franjas da malha urbana. Assim, o PMCMV ao mesmo tempo em que representa uma importante conquista para a política habitacional, tanto no que diz respeito ao número considerável de UHS, quanto ao fornecimento de largos subsídios, está atrelado à iniciativa privada, que favorece a implantação dos empreendimentos da população de menor renda predominantemente em áreas mais afastadas da cidade. 
A implantação de um programa de grande amplitude como o PMCMV traz transformações significativas na configuração do espaço urbano, devendo então contar com um planejamento não somente na construção do empreendimento, mas também em sua inserção na cidade, ou seja, a sua relação com as demais áreas a fim de evitar que o aumento populacional sobrecarregue os serviços públicos já existentes. Mediante a isso, é imprescindível que o plano diretor da cidade de Boa Vista (instituído em 2006) seja repensado levando em consideração este novo cenário que se descortinou a partir de 2009 com o surgimento deste programa.

\section{REFERÊNCIAS}

ARAGÃO, Thêmis Amorim. Influência das políticas habitacionais na construção do espaço urbano metropolitano de Fortaleza história e perspectivas. 2010. 132p. Dissertação (Mestrado em Planejamento Urbano e Regional) - Instituto de Pesquisa e Planejamento Urbano e Regional, Universidade Federal do Rio de Janeiro, Rio de Janeiro, 2010.

BALBINO, Michelle Lucas Cardoso. Programa Minha Casa Minha Vida e a colisão entre direitos fundamentais. Revista Brasileira de Políticas Públicas. v. 3, n. 1, Brasília, 2013. p. 51-76.

BASTOS, Rodrigo Dantas. Economia política do imobiliário: o Programa Minha Casa Minha Vida e o preço da terra urbana no Brasil. 2012. 106. Dissertação (Mestrado em Sociologia) - Instituto de Filosofia e Ciências Humanas, Universidade Estadual de Campinas, Campinas-SP, 2012.

BERNARDELLI, Maria Lúcia Falconi da Hora. Pequenas cidades na região de Catanduva - SP: papéis urbanos, reprodução social e produção de moradias. 2004. 350p. Tese (Doutorado em Geografia) Faculdade de Ciências e Tecnologia, Universidade Estadual Paulista Júlio de Mesquita Filho, 2004.

BOA VISTA. Lei Complementar no 924, de 28 de novembro de 2006. Dispõe sobre o Plano Diretor Estratégico e Participativo de Boa Vista e dá outras providências. Diário Oficial do Município de Boa Vista, Ano XII, no 1858, de 30 de novembro de 2006. Disponível em: < http://www.ajuri.org.br/emhur/Diario\%200ficial\%20do\%20Municipio\%20de\%20Boa\%20Vista\%201 858\%20-\%20Lei\%20Complementar\%20924,\%20925\%20e\%20926.pdf>. Acesso em 04/08/2014.

BRASIL. Decreto no 103, de 22 de abril de 1991. Autoriza a instituição do Fundo de Desenvolvimento Social (FDS) e dá outras providências. Diário Oficial União, Brasília, DF, 23 de abril de 1991. Disponível em: < http://www.planalto.gov.br/ccivil_03/decreto/Antigos/D103.htm>. Acesso em 25/10/2014.

BRASIL. Lei no 10.188, de 12 de fevereiro de 2001. Cria o Programa de Arrendamento Residencial, institui o arrendamento residencial com opção de compra e dá outras providências. Diário Oficial da União, Brasília, DF, 14 de fevereiro de 2001. Disponível em:< http://www.planalto.gov.br/ccivil_03/Leis/LEIS_2001/L10188.htm>. Acesso em: 11/10/2014.

BRASIL. Medida Provisória no 459, de 25 de março de 2009. Dispõe sobre o Programa Minha Casa, Minha Vida - PMCMV, a regularização fundiária de assentamentos localizados em áreas urbanas, e 
dá outras providências. Diário Oficial da União, Brasília, DF, 26 de março de 2009. Disponível em: <http://www.planalto.gov.br/ccivil_03/_Ato2007-2010/2009/Mpv/459.htm>. Acesso em 21/11/13.

BRASIL. Lei no 11.977, de 7 de julho 2009. Dispõe sobre o Programa Minha Casa, Minha Vida PMCMV e a regularização fundiária de assentamentos localizados em áreas urbanas e dá outras providências. Diário Oficial da União, Brasília, DF, 8 de julho de 2009. Disponível em: < http://www.planalto.gov.br/ccivil_03/_Ato2007-2010/2009/Lei/L11977.htm>. Acesso em: 21/11/13.

BRASIL. Decreto no 6.962, de 17 de setembro de 2009. Regulamenta as seções I, II, III e IV do Capítulo I e o Capítulo II da Lei no 11.977, de 7 de julho de 2009, que dispõe sobre o Programa Minha Casa, Minha Vida - PMVMV, e dá outras providências. Diário Oficial União, Brasília, DF, 18 de setembro de 2009. Disponível em: < http://www.planalto.gov.br/ccivil_03/_Ato20072010/2009/Decreto/D6962.htm >. Acesso em 21/11/13.

BRASIL. Medida Provisória 514, de 10 de dezembro de 2010. Altera a Lei no 11.977, de 7 de julho de 2009, que dispõe sobre o Programa Minha Casa, Minha Vida - PMCMV e a regularização fundiária de assentamentos localizados em áreas urbanas, as Leis nos 10.188, de 12 de fevereiro de 2001, 6.015, de 31 de dezembro de 1973, 6.766, de 19 de dezembro de 1979, e 4.591, de 16 de dezembro de 1964, e dá outras providências. Diário Oficial da União, Brasília, DF, 2 de dezembro de 2010. Disponível em: <http://www.planalto.gov.br/ccivil_03/_Ato2007-2010/2010/Mpv/514.htm >. Acesso em 21/11/13.

BRASIL. Decreto no 7.499, de 16 de junho de 2011. Regulamenta dispositivos da Lei no 11.977, de 7 de julho de 2009, que dispõe sobre o Programa Minha Casa, Minha Vida, e dá outras providências. Diário Oficial da União, Brasília, DF, 17 de jun. de 2011. Disponível em:< http://www.planalto.gov.br/ccivil_03/_Ato2011-2014/2011/Decreto/D7499.htm>. Acesso em 21/11/13.

BRASIL. Lei no 12.424, de 16 de junho de 2011. Altera a Lei no 11.977, de 7 de julho de 2009, que dispõe sobre o Programa Minha Casa, Minha Vida - PMCMV e a regularização fundiária de assentamentos localizados em áreas urbanas, e dá outras providências. Diário Oficial da União, Brasília, DF, 17 de jun. de 2011. Disponível em: < http://www.planalto.gov.br/ccivil_03/_Ato20112014/2011/Lei/L12424.htm>. Acesso em: 21/11/13.

BRASIL. Ministério das Cidades. Dispõe sobre as diretrizes gerais para aquisição e alienação de imóveis com recursos advindos da integralização de cotas no Fundo de Arrendamento Residencial FAR, no âmbito do Programa Nacional de Habitação Urbana - PNHU, integrante do Programa Minha Casa, Minha Vida - PMCMV. Portaria no 168 de 12 de abril de 2013. Diário Oficial da União, Brasília, DF, de 15 de abril de 2013. Disponível em: < http://www.cbic.org.br/sites/default/files/PORTARIA\%20168\%20DE\%20ABRIL\%202013\%20\%20PMCMV.pdf>. Acesso em: 22 de outubro de 2014.

BRASIL. Ministério das Cidades. Entre todos que precisam de uma casa, existem aqueles que precisam de mais apoio para conseguir a sua. [2013?]. Disponível em: < http://www.cidades.gov.br/images/stories/ArquivosCidades/Campanhas/Pac2/Cartilha_MC.pdf >. Acesso em 21/11/13. 
CAIXA ECONÔMICA FEDERAL. Cartilha: Minha Casa Minha Vida. [2010 ou 2011]. 37p. Disponível em: <http://www.adh.pi.gov.br/minha_casa_minha_vida.pdf>. Acesso em: 10 de junho de 2013.

CAIXA ECONÔMICA FEDERAL. Cartilha: Minha Casa Minha Vida. [2012?]. 48p. Disponível em: <http://www.imobiliariaconquistar.com.br/images/stories/Layout/MinhaCasaMinhaVida/CARTILHA COMPLETA.PDF>. Acesso em: 05 de janeiro de 2014.

CARDOSO, Adauto Lúcio; ARAGÃO, Thêmis Amorim. Do Fim do BNH ao Programa Minha Casa Minha Vida: 25 anos da política habitacional no Brasil. In: CARDOSO, Adauto Lúcio (org.). 0 Programa Minha Casa Minha Vida e seus efeitos territoriais. Rio de Janeiro: Letra Capital, 2013. p.17-65.

CORRÊA, Geovana de Medeiros. A habitação social em foco: uma abordagem sobre o Programa Minha Casa, Minha Vida. 2012. 190p. Dissertação (Mestrado em Economia) - Programa de PósGraduação em Economia, Universidade Federal de Santa Catarina, Florianópolis, 2012.

SOARES, Isabelle Oliveira. (Des) articulação entre política urbana e política habitacional: programa "Minha Casa, Minha Vida" e ZEIS nas cidades médias de Minas Gerais. 2012. 126p. Dissertação (Mestrado em Magister Scientiae) - Programa de Pós-Graduação em Arquitetura e Urbanismo, Universidade Federal de Viçosa, Viçosa-MG, 2012.

Trabalho enviado em 25 de junho de 2015.

Aceito em 02 de agosto de 2015. 